\title{
Multiobjective optimisation of a series hybrid electric vehicle using DIRECT algorithm
}

\author{
Abdelmoula Rihab*,**, Ben Hadj Naourez*, Chaieb Mohamed* and Neji Rafik* \\ *Department of Electrical Engineering, University of Sfax, Tunisia \\ **Corresponding Author: abdelmoula.rehab@gmail.com
}

$\begin{array}{ll}\text { Submitted: } & 26 / 06 / 2019 \\ \text { Revised: } & 21 / 10 / 2020 \\ \text { Accepted: } & 27 / 10 / 2020\end{array}$

\begin{abstract}
With the economic development, transportation in the city becomes more crowded. Furthermore, fuel consumption is causing a serious problem of pollution in the urban environment. Hybrid electric vehicles are considered as a good solution compared to conventional internal combustion engine vehicles. In order to solve those problems, the components parameters of a series hybrid electric vehicle are selected and tested with the ADvanced VehIcle SimulatOR (ADVISOR) simulation tool, which is a software-based on Matlab_simulink. Then, an optimisation was done to minimise simultaneous fuel consumption and emissions ( $\mathrm{HC}, \mathrm{CO}$, and $\mathrm{NOx}$ ) of the vehicle engine. In addition, the driving performance requirements are also examined during the urban dynamometer driving schedule (UDDS) to fix their optimal control parameters. Finally, the results show that those steps help reduce fuel consumption and emissions while guaranteeing vehicle performance. Hence, the series hybrid electric vehicle greatly improves fuel economy and reduces toxic emissions.
\end{abstract}

Keywords: fuel consumption; pollution; series hybrid electric vehicle; emissions; optimise.

\section{INTRODUCTION}

The development of clean transportation with more fuel economy and fewer emissions is becoming mainstream in the automotive company due to the crisis aggravation of the environmental problems and the energy in the word. The internal combustion engines (ICEs) used in vehicles present various disadvantages that have harmful effects on human, animal, and even plant health. Therefore, hybrid electric vehicle (HEV), which is a combination of a conventional vehicle and electric vehicle, can be a solution. It allows reducing the ICE size and the fuel consumption (FC), and it improves its efficiency compared to the conventional vehicle, as well as lowering the battery size as to be used in electric vehicle. Moreover, HEVs do not need an external battery charge and new infrastructure; for this reason, in recent years, many researchers have focused on this type of vehicle. These factors make HEV a viable solution to reduce environmental pollution and oil depletion problems. Thus, hybrid technology is an important choice for future cars (Cheng et al., 2017).

There are different types of HEVs; in this work, a series hybrid electric vehicle (SHEV) is considered. Thereafter, drive train components and control strategy (CS) parameters of the SHEV are fixed using the simulator ADVISOR. ADVISOR is a vehicle simulator, which can simulate different types of vehicles while acting on engine, electric motor, accessories, driving cycles, etc. Likewise, it can calculate the energy consumption, emissions, and vehicle components performance and evaluate the accuracy of the results at the same time. It can also control the energy management of the vehicle. The vehicle is tested, and subsequently an optimisation of fuel consumption (FC) and emissions, using the dividing rectangles algorithm (DIRECT) algorithm, is made. Since the dimensioning of SHEV power train 
components and their control strategy are closely related, a simultaneous optimisation is justified (Baumann et al., 2000; Panday et al., 2014). The optimisation phase is considered as a multidisciplinary research work that examines two main objectives such as reducing FC and limiting pollutant emissions (Yadav, 2019). An adjustment of the control strategy parameters allows a better sizing of the power train components while satisfying the vehicle performance constraints (Chris et al., 2011; Hao et al., 2016).

\section{THE PROPOSED APPROCH FOR VEHICLE OPTIMISATION}

In order to test the SHEV proposed in this work, the ADVISOR simulator is used. Afterwards, based on specifications definite, the vehicle drivetrain component is auto-sized and identified while respecting the recommended performance using ADVISOR. FC and emissions are evaluated and analysed over different driving cycles for two types of CS mostly used for this type of vehicle. Subsequently, an optimisation of the SHEV is done using the DIRECT algorithm to minimise the $\mathrm{FC}$ and limit the exhaust emissions (CO, $\mathrm{HC}$, and $\mathrm{NOx})$ and to ensure good driving performance. During this optimisation, the parameters taken into account are the design parameters of the drive train, and parameters related to the CS.

A strategy will be proposed, thus, allowing the coupling between the ADVISOR vehicle simulator and the optimisation procedure based on DIRECT. Finally, simulation results will be presented and analysed for different optimisation cases in order to specify the optimal SHEV.

The approach used is explained as presented in Figure 1: first, the vehicle is modelled in ADVISOR, and then this model is integrated into a computational loop. The vehicle model with the initial value is simulated; and the value of the objective function is found. Meanwhile, the constraints, which are the vehicle performances, are considered.

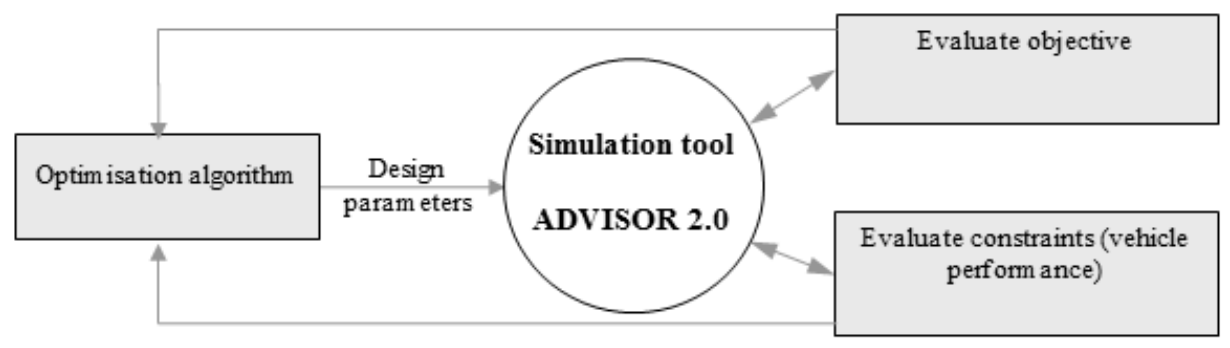

Figure 1. The approach used to optimise the SHEV using ADVISOR.

Thereafter, the simulation results are fed back to the optimisation algorithm, which outputs a new value set of design variables. Again, the vehicle is simulated to obtain the objective function value and the constraint functions results. This loop keeps on until it reaches one of the stop criteria for the optimisation algorithm.

\section{VEHICLE MODEL}

SHEV is specified by good energy efficiency in all-electric mode, and a simple ICE control (Ben Halima et al., 2018). The series architecture is closest to the all-electric vehicle, where the EM is directly connected to the wheels, and it provides all the power. The selected SHEV power train, as shown in Figure 2, consisted of a downsized ICE, an electric motor (EM) of traction, and a battery. A single EM propels the SHEV from two power sources either from the ICE to the generator or from the battery (Krithika et al., 2017). So, the principle of energy transformation in this type of hybrid electric vehicle is in series.

As the ICE has no mechanical connection to the transmission, it can be regulated to operate at its peak efficiency point (Souffran, 2012). Therefore, the ICE is decoupled from the road load so that it will not undergo abrupt changes in operating conditions and will have little time to idle, which reduces emissions.

The SHEV used in this work is described in Table 1. 


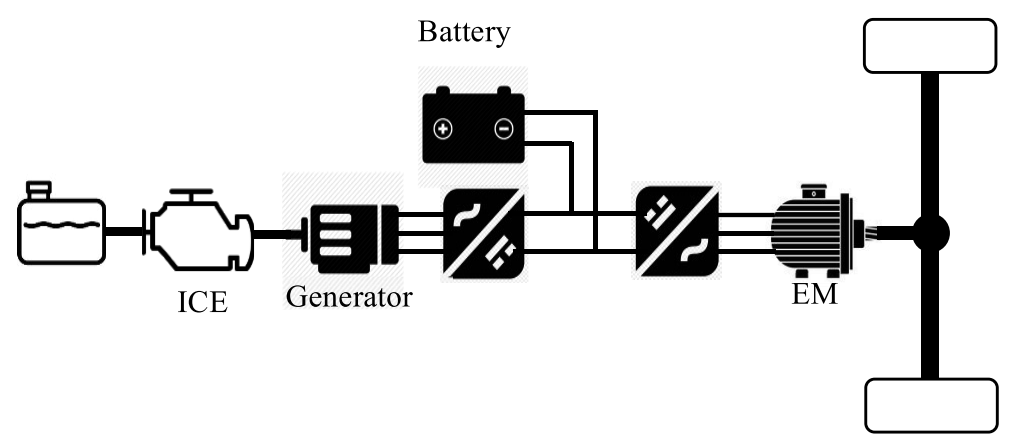

Figure 2. SHEV power train design.

Table 1. Design variable.

\begin{tabular}{|c|c|c|c|}
\hline Description & Symbol & Values & Unit \\
\hline Calculated mass & $\mathrm{M}_{\mathrm{v}}$ & 1000 & $\mathrm{~kg}$ \\
\hline Coefficient of rolling resistance & $\mathrm{C}_{\mathrm{rr}}$ & 0.015 & $/$ \\
\hline Aerodynamic drag coefficient & $\mathrm{C}_{\mathrm{x}}$ & 0.4 & $\mathrm{~m} 2$ \\
\hline Vehicle front area & $\mathrm{S}_{\mathrm{f}}$ & 2 & $\mathrm{~m} / \mathrm{s}$ \\
\hline Vehicle speed & $\mathrm{V}$ & $\mathrm{Cycle}$ & $\mathrm{m} / \mathrm{s}$ \\
\hline Wind speed & $\mathrm{V}_{\mathrm{w}}$ & 0 & $\mathrm{~m} / \mathrm{s} 2$ \\
\hline Acceleration of gravity & $\mathrm{g}$ & 9.81 & $\%$ \\
\hline Angle of the slope & $\alpha$ & 5 & $\mathrm{~kg} / \mathrm{m} 3$ \\
\hline Air density & $\rho$ & 1.28 & $\mathrm{~m}$ \\
\hline Wheel radius & $\mathrm{R}_{\mathrm{wheel}}$ & 0.26 & $\mathrm{~s}$ \\
\hline Starting time (from 0 to30 km/h) & $\mathrm{t}_{\mathrm{s}}$ & 4 & $\mathrm{~km} / \mathrm{h}$ \\
\hline Vehicle maximum speed & $\mathrm{V}_{\text {max }}$ & 100 & $\mathrm{Ah}$ \\
\hline Capacity of the battery cell & $\mathrm{C}_{\text {cell }}$ & 6 & 180 \\
\hline Battery module number & $\mathrm{Mod}_{\mathrm{B}}$ & & $\mathrm{module}$ \\
\hline
\end{tabular}

The SHEV should supply the necessary traction force to surmount resistive forces. The energy system is determined by the vehicle power demand. The model that describes the dynamics of the vehicle allows calculating the energy needed to move the vehicle.

Consider a vehicle, moving at a speed $\mathrm{V}$ on a slope angle $\alpha$. The propulsive force for the displacement of the vehicle called the traction force $F_{t}$ must withstand the rolling resistance $F_{r r}$, the aerodynamic drag $F_{\text {aero }}$, the climbing resistance force $F_{p}$, and the acceleration force of the vehicle $F_{a}$ (Abdelmoula, 2018). Those forces are expressed in Equations. 1, 2, 3, 4, and 5, respectively. 


$$
\begin{aligned}
& \mathrm{F}_{\mathrm{t}}=\mathrm{F}_{\mathrm{rr}}+\mathrm{F}_{\text {aero }}+\mathrm{F}_{\mathrm{p}}+\mathrm{F}_{\mathrm{a}} \\
& \mathrm{F}_{\mathrm{rr}}=\mathrm{M}_{\mathrm{v}} \mathrm{gC}_{\mathrm{rr}} \\
& \mathrm{F}_{\text {aero }}=\frac{1}{2} \rho \mathrm{S}_{\mathrm{f}} \mathrm{C}_{\mathrm{x}}\left(\mathrm{V}+\mathrm{V}_{\mathrm{w}}\right)^{2} \\
& \mathrm{~F}_{\mathrm{p}}=\mathrm{M}_{\mathrm{v}} \mathrm{g} \sin (\alpha) \\
& \mathrm{F}_{\mathrm{a}}=\sigma \mathrm{M}_{\mathrm{v}} \gamma
\end{aligned}
$$

The wheels speed starts from zero until it reaches the base speed. During this phase, the traction motor applies a constant starting torque on the wheels. From a base speed to the maximum speed of the vehicle, the motor exerts a torque, which decreases proportionally to the motor speed (Abdelmoula et al., 2016). Figure 3 shows the torque as a function of EM speed.

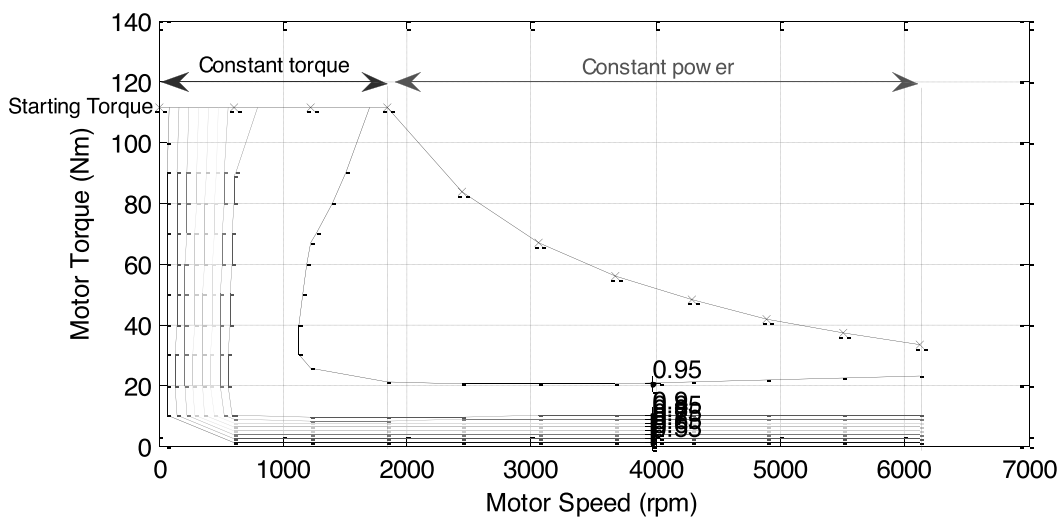

Figure 3. EM torque as function of speed.

The torque and the power at the wheels are presented by the Equations 6 and 7, respectively (Chaieb, 2011).

$$
\begin{aligned}
\mathrm{T}_{\text {wheel }} & =\mathrm{T}_{\mathrm{s}} \frac{\mathrm{V}_{\mathrm{b}}}{\mathrm{V}} \\
\mathrm{P}_{\text {wheel }} & =\mathrm{T}_{\mathrm{s}} \frac{\mathrm{V}_{\mathrm{b}}}{\mathrm{R}_{\text {wheel }}}
\end{aligned}
$$

The vehicle must reach the base speed for a time $t_{s}$, in this condition, and with neglecting the aerodynamic force and the rolling friction force, the starting torque $\mathrm{T}_{\mathrm{s}}$ takes the following expression:

$$
\mathrm{T}_{\mathrm{s}}=\mathrm{R}_{\text {wheel }}\left(\frac{\sigma \mathrm{M}_{\mathrm{v}} \mathrm{R}_{\text {wheel }} \mathrm{V}_{\mathrm{b}}}{\mathrm{t}_{\mathrm{s}}}+\mathrm{M}_{\mathrm{v}} \mathrm{g} \sin (\alpha)\right)
$$

\section{CONTROL STRATEGY FOR SHEV}

The CS is a compilation of algorithms in the controller of the vehicle that manipulates the energy flux between power train components in an optimal way. A badly treated CS can lead to absurd results, with a similar consumption even higher than that of equivalent conventional vehicle (Kermani, 2009). Hence, the presence of two source of energy in the SHEV requires an efficient sharing of power between those different sources. Improving fuel economy with reduced emissions of the SHEV depends on their CS. It makes it possible to choose the operating mode adopted for the vehicle. 
The CS determines at which torque and speed the ICE must operate, to generate electrical energy via the generator, taking into account the conditions of the EM, the battery, and/or the ICE itself. Usually, such a strategy is designed to minimise fuel use and emissions or maximise battery life (Brooker et al., 2002). Two popular CSs of SHEVs, such as thermostat control strategy (TCS) and power follower control strategy (PFCS), will be described later.

\section{Thermostat control strategy}

TCS is a simple and robust control system; it is the most conventional control strategy for SHEV, and it allows a good fuel economy (Shabbir, 2015). The TCS relies on the ICE and the generator to provide the electrical energy demanded by the vehicle. The ICE is used to maintain the charge in the battery. The power distribution in this strategy depends essentially on the battery state of charge (SOC), as explained in Figure 4. The SOC value must be between the upper SOC (cs_hi_soc) and lower SOC limits (cs_lo_soc) by turning on or off the ICE.

The operating principle of the TCS is explicated along these lines:

- The ICE turns on just when the SOC attains its inferior limit (cs_lo_soc).

- The ICE turns off just when the SOC reaches its high limit (cs_hi_soc); if its previous state was on, it goes off after reaching the cs_hi_soc, and it goes out.

- The ICE operates at its most efficient operating point.

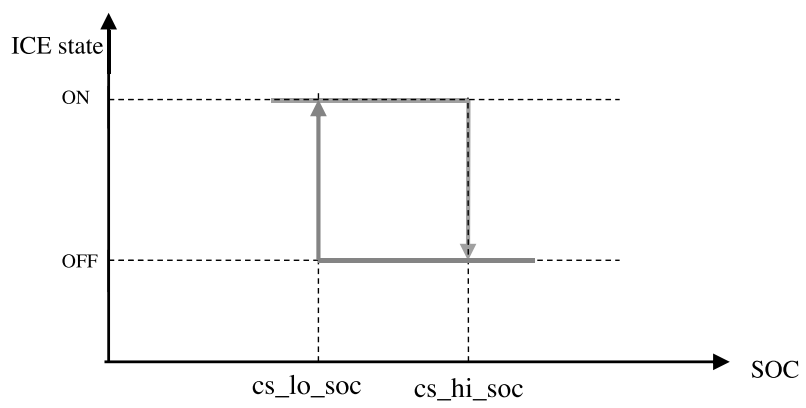

Figure 4. Determination of ICE status (on / off) in TCS.

\section{Power follower control strategy}

The basic idea of the PFCS is to consider the genset (ICE + generator) as the main power source and the supervisory control as the means of adjusting the output power of the genset to follow the vehicle driving power. The group is active in almost all driving conditions, except in cases where low ICE power is required and the SOC is greater than cs_hi_soc. The overall state of the genset control is based on Figure 5 (Gao et al., 2009).

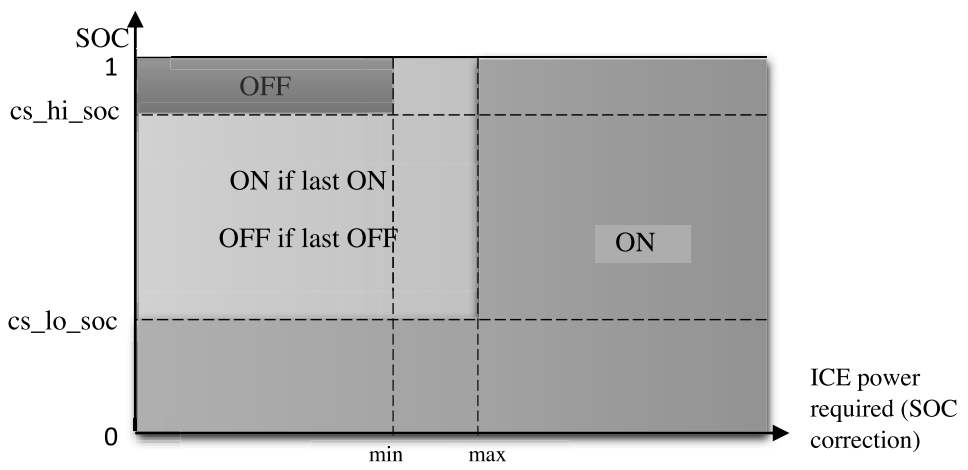

Figure 5. Determination of ICE status (on / off) in PFCS. 
The PFCS used for SHEV offers flexibility in the operation of the ICE as follows:

- The ICE can be disabled if the battery SOC is too high.

- The ICE can be activated again if the power required by the bus is high enough.

- The ICE can be activated again if the SOC is too low.

When the ICE is turned on, its output power tends to follow the power required by the bus, taking into account the losses in the generator so that the power output of the generator matches the energy requirements of the bus.

For this study, the SHEV can be fuelled only using fuel; it cannot be recharged using the power grid. Hence, the diminution of FC and gas emissions is essential. The FC and emissions can be evaluated using the ADVISOR simulator. When evaluating the FC, SHEV must meet some additional conditions. In fact, the SOC measured at the beginning and at the end of the cycle must be substantially equal. This condition ensures a zero-energy balance in the energy storage system, to have consumption only from fuel (Rousseau, 2008). This correction routine, called zero $\triangle \mathrm{SOC}$, adjusts the initial SOC until the execution of the simulation produces nearly zero in the tolerance band between the initial and the final battery SOC of the mission (initial SOC-final SOC $\leq 0.005$ ). Hence, the routine will be run until $\triangle$ SOC converges (Brooker et al., 2002).

Table 2 shows the FC and emissions of the SHEV in three driving cycles ECE_EUDC_LOW, UDDS, and SCO3 in the case of both TCS and PFCS.

The results show that FC for TCS is lower than PFCS, while emissions are slightly higher. In addition, the ICE operates at its most efficient point of load for the TCS strategy. Therefore, the TCS will be chosen later for the SHEV.

Table 2. Fuel consumption and emissions of the SHEV.

\begin{tabular}{|c|c|c|c|c|c|}
\hline \multirow{2}{*}{ Cycle } & \multirow{2}{*}{$\begin{array}{c}\text { Control } \\
\text { strategy }\end{array}$} & $\begin{array}{c}\text { Fuel consumption } \\
(\mathbf{l} / \mathbf{1 0 0} \mathbf{~ k m})\end{array}$ & \multicolumn{3}{|c|}{ Emissions (g/km) } \\
\cline { 3 - 6 } & TCS & 5.6 & 0.209 & 1.038 & 0.353 \\
\hline \multirow{2}{*}{ ECE_EUDC_LOW } & PFCS & 6 & 0.192 & 0.908 & 0.37 \\
\cline { 2 - 6 } & TCS & 5.7 & 0.209 & 1.026 & 0.354 \\
\hline \multirow{2}{*}{ UDDS } & PFCS & 6.2 & 0.208 & 0.952 & 0.332 \\
\cline { 2 - 6 } & TCS & 5.3 & 0.329 & 1.805 & 0.481 \\
\hline \multirow{2}{*}{ SCO3 } & PFCS & 5.7 & 0.325 & 1.721 & 0.483 \\
\hline
\end{tabular}

\section{OPTIMISATION OF SHEV USING DIRECT ALGORITHM Objective Function}

When designing the SHEV, we aim for several simultaneous objectives such as minimizing FC and exhaust emissions ( $\mathrm{HC}, \mathrm{CO}$, and $\mathrm{NOx}$ ) while ensuring driving performance requirements. Typical ICE operating points indicate that minimum $\mathrm{FC}$ does not necessarily result in minimum emissions (Figure 6), which requires a compromise solution (Montazeri Gh et al., 2006). 


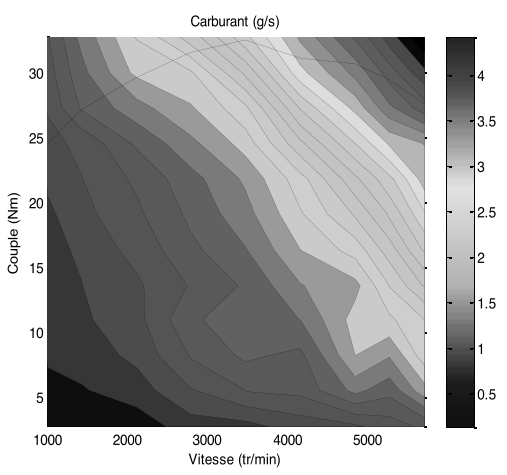

(a)

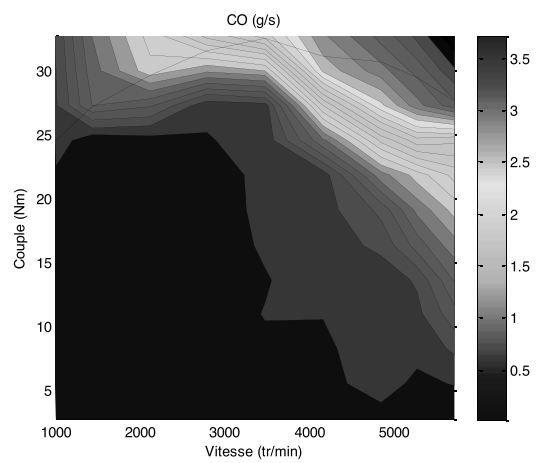

(c)

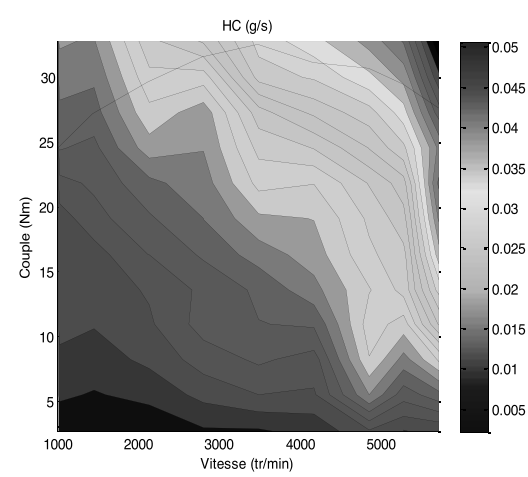

(b)

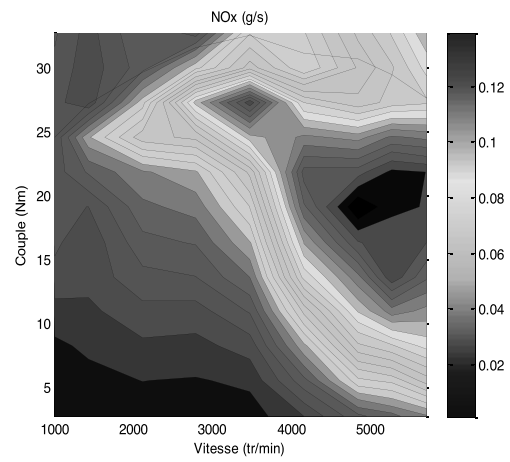

(d)

Figure 6. Fuel consumption and emission ( $\mathrm{HC}, \mathrm{CO}$, and $\mathrm{NOx})$ maps based on torque and speed of ICE Geo 1.0L 41 kW. (a) Fuel consumption; (b) HC; (c) CO; (d) NOx.

So, in this study, a multiobjective optimisation method based on weighting aggregation is used, which is the simplest and most widely classical optimisation method used for solving multiobjective optimisation problems. In this context, each objective function is multiplied by a weight and summed to form a composite objective function. The weight of an objective function is usually chosen in proportion to their relative importance in the problem. However, it is possible that the different objectives have different orders of magnitude. Thus, to set appropriate weight values and make goals equally important, standardization of goals is needed (Desai, 2010). In this work, a multiobjective optimisation is defined to minimise the FC and the exhaust emissions (CO, HC, and NOx). The objective function is defined as follows (Desai, 2010; Janiaud, 2011):

$$
\mathrm{F}(\mathrm{x})=\mathrm{w}_{1} \overline{\mathrm{FC}}+\mathrm{w}_{2} \overline{\mathrm{HC}}+\mathrm{w}_{3} \overline{\mathrm{CO}}+\mathrm{w}_{4} \overline{\mathrm{NO}_{\mathrm{x}}}
$$

All partial functions are standardised. $\mathrm{w}_{1}, \mathrm{w}_{2}, \mathrm{w}_{3}$ and $\mathrm{w}_{4}$ are also defined as the weighting factors that are assigned to each function.

Different optimisation cases are studied along the UDDS driving cycle. Table 3 shows the values of the weighting factors used during the optimisation procedure.

Table 3. Weighting factors values used in multiobjective optimisations.

\begin{tabular}{|c|c|c|c|c|}
\hline Optimisation & w1 & w2 & w3 & w4 \\
\hline Case 1 & 0.7 & 0.1 & 0.1 & 0.1 \\
\hline Case 2 & 0.6 & 0.1 & 0.2 & 0.1 \\
\hline Case 3 & 0.5 & 0.1 & 0.3 & 0.1 \\
\hline Case 4 & 0.4 & 0.1 & 0.4 & 0.1 \\
\hline
\end{tabular}




\section{Performance constraints}

The constraints in some vehicle optimisation problems are inequality constraints, which derive from the limits of the vehicle's dynamic performance and the SOC variation. The SHEV must reach a certain speed in a given time during an acceleration test. In addition, our vehicle must have a zero energy balance at the battery between the beginning and the end of the cycle to stimulate the true FC and gas emissions values. The performance of the SHEV to be optimised is shown in Table 4.

Table 4. Performance constraints used in multiobjective optimisations.

\begin{tabular}{|l|l|}
\hline Constraint 1: Acceleration time & $\begin{array}{l}\text { - The acceleration time from } 0 \text { to } 30 \mathrm{~km} / \mathrm{h} \text { is } \leq 4 \mathrm{~s} \\
\text { - The acceleration time from } 0 \text { to } 100 \mathrm{~km} / \mathrm{h} \text { is } \leq 38.2 \mathrm{~s}\end{array}$ \\
\hline Constraint 2: Grad ability & $\begin{array}{l}\text { - The slope is } 5 \% \text { at } 50 \mathrm{~km} / \mathrm{h} \text { for an initial } \mathrm{SOC}=80 \% \\
\text { and a final } \mathrm{SOC} \geq 40 \% .\end{array}$ \\
\hline Constraint 3: Trace miss & \begin{tabular}{l} 
- $\begin{array}{l}\text { Difference between the requested speed of the } \\
\text { driving cycle and the speed reached by the vehicle } \\
\text { every second is } \leq 3.2 \mathrm{~km} / \mathrm{h} .\end{array}$ \\
\hline Constraint 4: SOC balancing
\end{tabular}$\quad \begin{array}{l}\text { The difference between the final state of charge and } \\
\text { the initial state of charge } \triangle \mathrm{SOC} \text { is } \leq 0.5 \% .\end{array}$ \\
\hline
\end{tabular}

\section{Optimisation parameters}

Optimisation of SHEV involves many design variables, and it is awkward to optimise all of them. In this work, only the main powertrain components and CS system parameters that have important impacts on the performance of the vehicle are taken into account. Eight parameters were considered: four design parameters of the drive train and four parameters related to the CS. The description of these variables with their lower and upper bounds is presented in Table 5.

Table 5. Optimisation parameters description.

\begin{tabular}{|c|c|c|c|}
\hline Design parameters & Description & $\begin{array}{l}\text { Lower } \\
\text { bound }\end{array}$ & $\begin{array}{l}\text { Upper } \\
\text { bound }\end{array}$ \\
\hline mc_trq_scale & Motor Controller torque scaling factor & 0.8 & 1.5 \\
\hline fc_trq_scale & Fuel converter torque scaling factor & 0.32 & 0.6 \\
\hline gc_trq_scale & Generator Controller torque scaling factor & 0.28 & 0.84 \\
\hline ess_module_num & Energy Storage System module number & 170 & 190 \\
\hline $\begin{array}{c}\text { Control strategy } \\
\text { parameters }\end{array}$ & Description & $\begin{array}{l}\text { Lower } \\
\text { bound }\end{array}$ & $\begin{array}{l}\text { Upper } \\
\text { bound }\end{array}$ \\
\hline cs_hi_soc & highest desired battery state of charge & 0.6 & 0.9 \\
\hline cs_lo_soc & lowest desired battery state of charge & 0.3 & 0.5 \\
\hline cs_max_pwr (W) & $\begin{array}{l}\text { cs_max_pwr*fc_spd_scale*fc_trq_scale is the maximum } \\
\text { power commanded of the fuel converter unless SOC }<\text { cs_lo_soc }\end{array}$ & 20503.51 & 41007 \\
\hline cs_min_pwr (W) & $\begin{array}{l}\text { cs_min_pwr*fc_spd_scale*fc_trq_scale is the minimum power } \\
\text { commanded of the fuel converter }\end{array}$ & 10251.75 & 20503.51 \\
\hline
\end{tabular}

The objective of this work is to optimise a SHEV in order to decrease the FC and emissions on an urban driving cycle UDDS (Figure 7). The basic configuration of the SHEV used for the simulation is given in Table 6. 


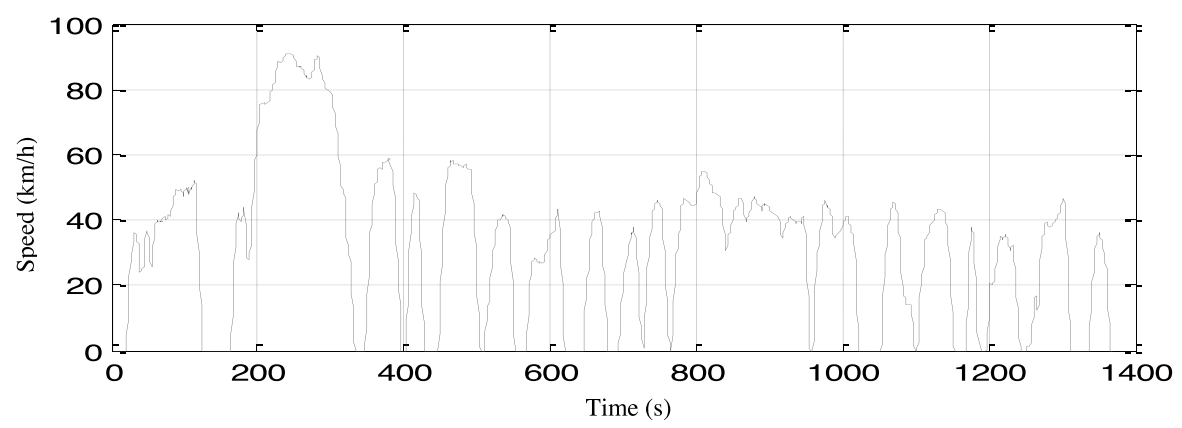

Figure 7. UDDS Cycle.

Table 6. SHEV configuration.

\begin{tabular}{|c|c|c|}
\hline \multirow{4}{*}{ MSAP } & Variables & values \\
\hline \multirow{4}{*}{ ICE } & mc_trq_scale & 1 \\
\cline { 2 - 3 } & mc_spd_scale & 1 \\
\cline { 2 - 3 } & Max power (kW) & 21.5 \\
\cline { 2 - 3 } & Max speed (RPM) & 6121 \\
\cline { 2 - 3 } & fc_trq_scale & 0.4 \\
\cline { 2 - 3 } & fc_spd_scale & 1 \\
\cline { 2 - 3 } & Max power(kW) & 16 \\
\hline \multirow{4}{*}{ Generator } & Max speed (RPM) & 5700 \\
\cline { 2 - 3 } & gc_trq_scale & 0.56 \\
\cline { 2 - 3 } & gc_spd_scale & 0.857 \\
\cline { 2 - 3 } & Max power (kW) & 16 \\
\hline \multirow{4}{*}{ Battery } & Max speed (RPM) & 6000 \\
\cline { 2 - 3 } & ess_module_num & 180 \\
\cline { 2 - 3 } & ess_cap_scale & 6 \\
\cline { 2 - 3 } & capacity (Ah) & 1 \\
\hline
\end{tabular}

\section{Application of DIRECT algorithm}

The DIRECT algorithm was developed by Donald R. Jones (Jones, 2001). This algorithm represents Lipschitzian optimisation with the elimination of the Lipschitz constant.

This algorithm does not use derivatives. Other algorithms that do not use derivatives can be mentioned such as simulated annealing (SA), genetic algorithm (GA), and particle swarm optimisation (PSO). These types of algorithm are often the best global algorithms because they cover the entire design space (Deb, 2001; Chris et al., 2011; Zhang et al., 2011). In several research studies, GA is most commonly used to optimise HEVs (Montazeri-Gh et al., 2006; Varesi et al., 2011; Jun et al., 2014; Panday et al., 2016). The PSO algorithm has also been exploited to optimise control parameters and to minimise FC (Wu et al., 2008; Chen et al., 2015; Xiong et al., 2015). Other works have optimised the HEV design parameters and control strategy using the DIRECT algorithm (Rousseau et al., 2007; Panday et al., 2014; Borthakur et al., 2018). Keith Wipke agrees that the DIRECT algorithm is the best algorithm without a derivative to find the optimal overall solution. In this context, Chris and Wipke applied the DIRECT method to overcome the limitation of gradient methods; they concluded that nonderivative methods are more effective than gradient-based methods (Wipke et al., 2001; Chris et al., 2011). In this study, the DIRECT algorithm was used. This choice was made because DIRECT is dedicated for global optimization, and it focuses on stability and accuracy, 
which is suitable for optimising models of complex vehicles, including SHEVs (Jones, 2001). It covers the entire design space while using the sample information to decide the search direction (Chris et al., 2011). This algorithm is suitable for difficult optimisation problems with related constraints and real values objective function.

DIRECT algorithm has many strong points. In fact, this algorithm is a black-box, so the need to assuming the gradients' availability and information about objective function is not necessary. Further, it guarantees finding the global minimum when the fitness function is continuous. Moreover, DIRECT is a deterministic algorithm, so it can find the optimal results with only one run. The DIRECT algorithm uses a pattern of hyperdimensional adaptive mesh to search the entire design space in order to find the optimum. Three first iterations of a 2D DIRECT optimisation problem are presented in Figure 8 (Gao et al., 2005). Dark rectangles are the rectangles selected as optimal for division in this iteration. DIRECT makes effective compromise by choosing the right lower convex hull (Finkel et al., 2010).

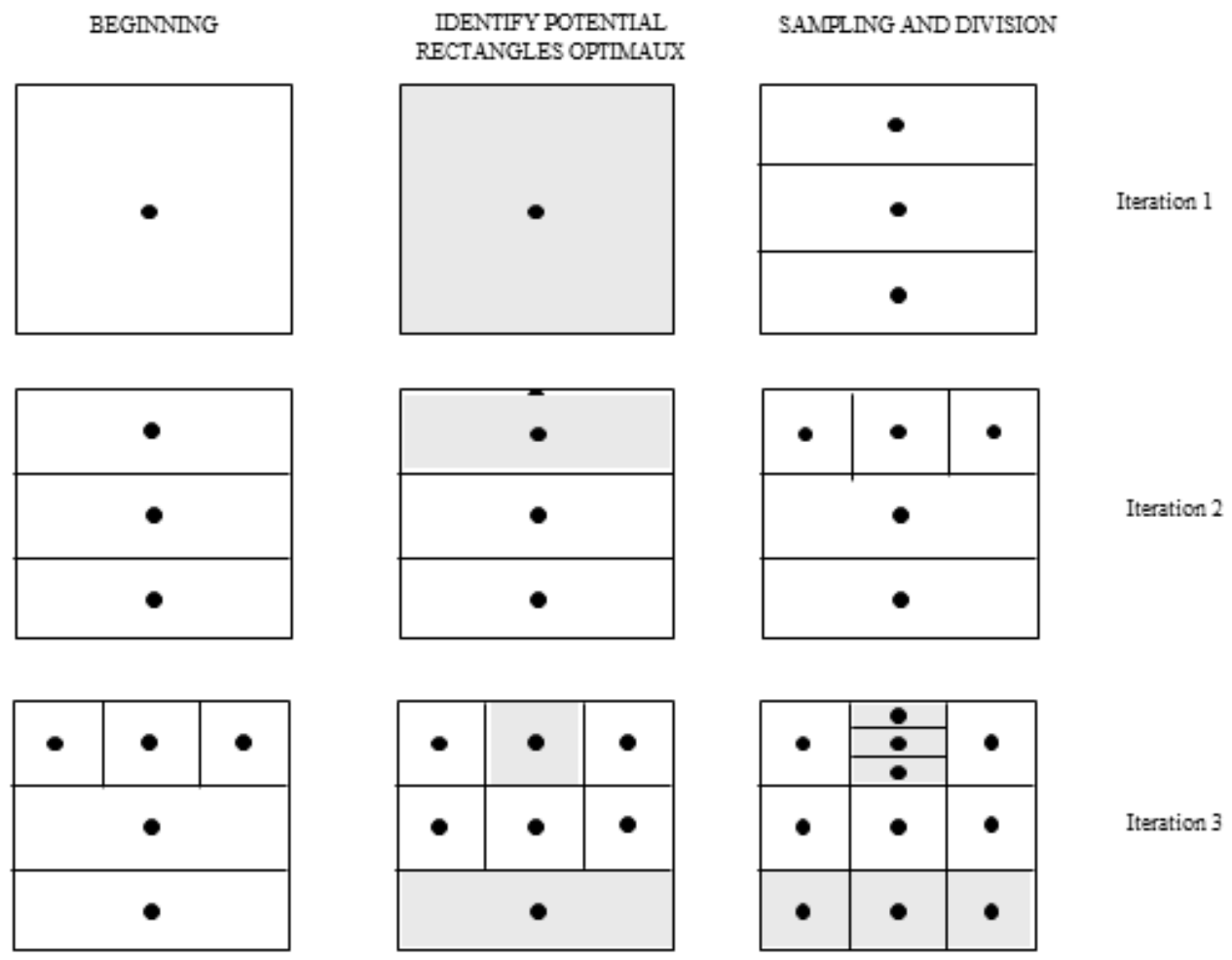

Figure 8. First three iterations of the 2D DIRECT algorithm.

The optimising procedure of the DIRECT algorithm is presented in Figure 9. First, the algorithm starts with an evaluation of the objective function at the central point of the first hyper-rectangle that represents the whole domain, and it considered as an initial objective function. Secondly, the program chooses a potential optimal hyperrectangle and divides it into three equal regions. Then, the objective function is calculated at the centre of each region. After that, the algorithm compares them with the minimum value collected in the last iteration. If this value is lower than that of the previous objective function, the latter is updated and stored; besides, the potential optimal hyperrectangle is updated. The optimisation using DIRECT algorithm will stop only when the maximum number of the evaluated function or the maximum number of iterations is reached (Hao et al., 2016). 


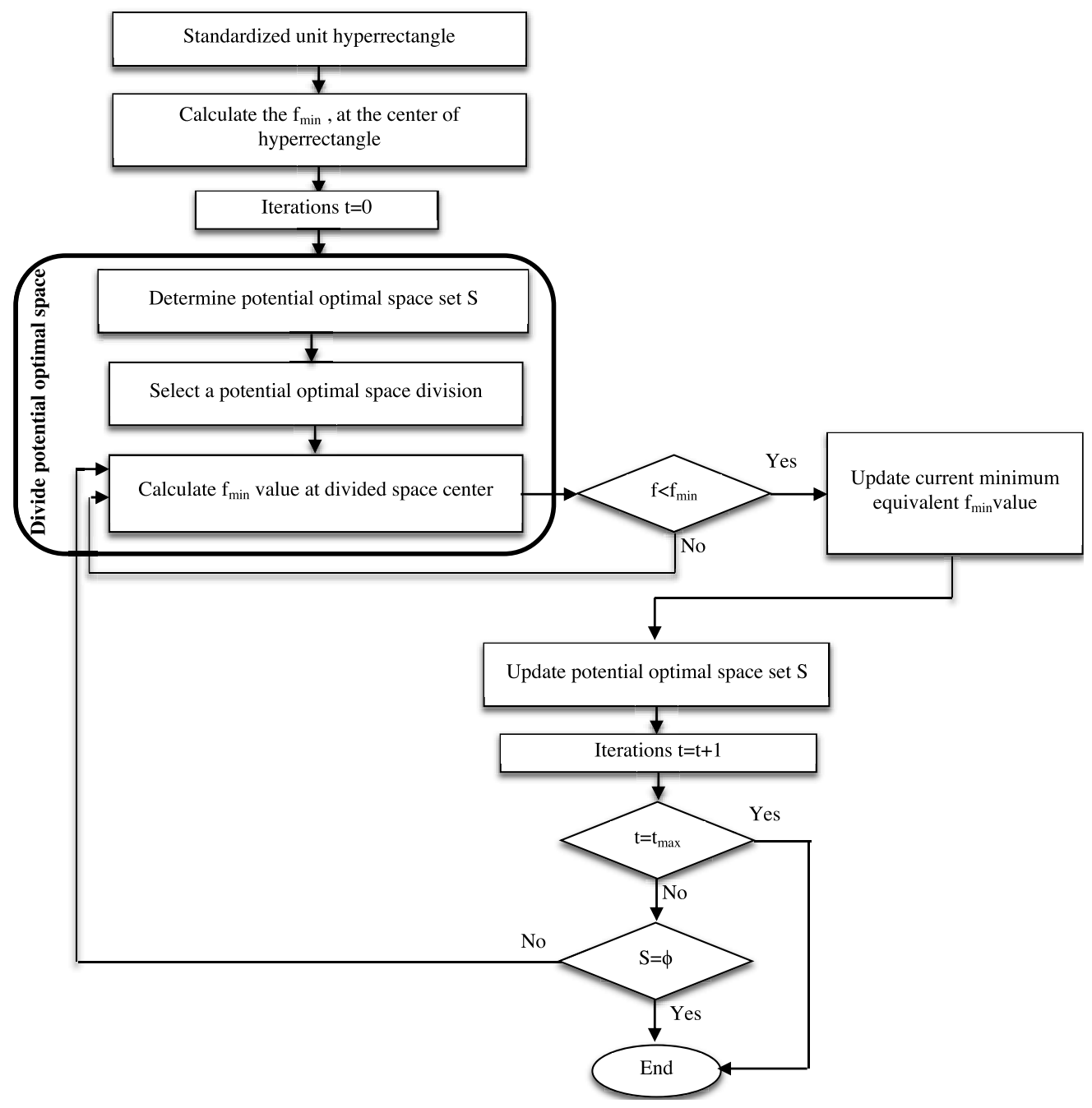

Figure 9. Optimisation process of DIRECT algorithm.

\section{SIMULATION CASE AND RESULTS ANALYSIS}

The algorithm DIRECT is looped with ADVISOR, and the optimisation problem is done. A decrease in the FC and emissions was observed in the four optimisation cases. Figure 10 shows the behaviour of the objective function for the four optimisation cases under UDDS driving cycle.

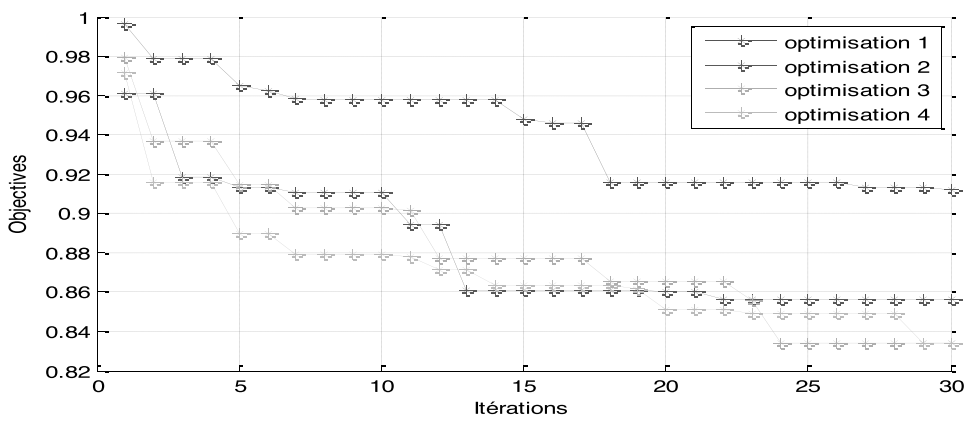

Figure 10. Objective functions for optimisation cases. 
Table 7 and Figure 11 summarise values of the objective functions, the optimal design parameters, and the performance criteria for different optimisation cases.

A decrease in the $\mathrm{FC}$ and emissions in the four optimisation cases compared to preoptimisation values is clear. The acceleration times obtained during the optimisation respect the constraints already fixed. The constraint $\Delta \mathrm{SOC} \leq 0.5 \%$ is true only in the first and the second optimisation cases. Furthermore, according to Figure 10, the vehicle has followed the UDDS driving cycle in all the optimisation cases, because the difference between the required and the reached speed during the four optimisation cases does not exceed $2 \mathrm{mph}$. To summarize, the results found confirmed the satisfaction of driving performance only for the two first optimisation cases. To explain the four optimisation cases, each case will be analysed severely afterwards, drawing on Figure 11 and Table 7:

- For the first case of optimisation, the objective function shows a decrease, which leads to a decrease in FC and emissions; moreover, the performance constraints are satisfied.

- For the second case of optimisation, the objective function presents a decrease, and therefore a decrease in the FC and emissions, and the performance constraints are also satisfied.

- For the third case of optimisation, it is clear that the objective function presents a minimisation, but the constraints are not all satisfied; indeed, $\triangle \mathrm{SOC}=0.505 \%$, whereas the constraint requires that $\Delta \mathrm{SOC} \leq 0.5 \%$.

- In the same way, for the fourth, certainly, the objective functions are to minimise, but the constraint $\Delta \mathrm{SOC} \leq 0.5 \%$ is not right; in fact, $\triangle \mathrm{SOC}=0.645 \%$.
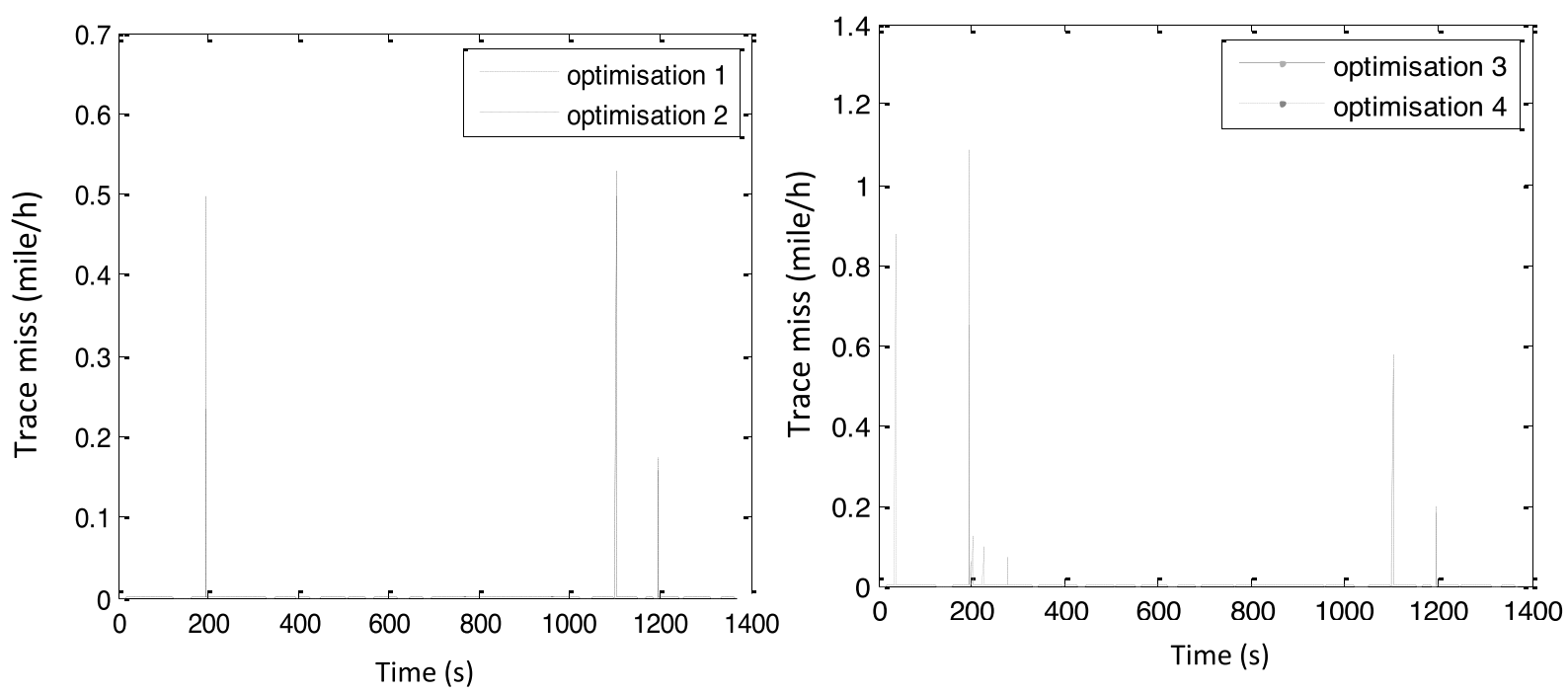

Figure 11. Difference between required and achieved speed for different optimisation cases. 
Table 7. SHEV configuration for different simulation case.

\begin{tabular}{|c|c|c|c|c|c|c|}
\hline \multicolumn{2}{|r|}{ Items } & Initial value & 1 & 2 & 3 & 4 \\
\hline \multirow{5}{*}{ 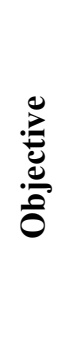 } & Objective function & -- & 0.911 & 0.856 & 0.833 & 0.834 \\
\hline & Fuel (1/100 km) & 5.7 & 5.3 & 5.4 & 5.3 & 5.4 \\
\hline & HC & 0.209 & 0.182 & 0.171 & 0.174 & 0.188 \\
\hline & $\mathrm{CO}$ & 1.026 & 0.808 & 0.735 & 0.682 & 0.706 \\
\hline & NOx & 0.354 & 0.249 & 0.219 & 0.232 & 0.238 \\
\hline \multirow{8}{*}{$\frac{\frac{n}{0}}{\frac{0}{0}}$} & mc_trq_scale/ $\mathbf{P}_{\text {EM }}(\mathrm{kW})$ & $1 / 21.5$ & $1.12 / 24$ & $1.175 / 25$ & $1.072 / 23$ & $1.046 / 22$ \\
\hline & fc_trq_scale / $P_{\text {ICE }}(\mathrm{kW})$ & $0.4 / 16$ & $0.337 / 14$ & $0.327 / 13.5$ & $0.327 / 13.5$ & $0.358 / 15$ \\
\hline & gc_trq_scale / $P_{G}(k W)$ & $0.56 / 16$ & $0.377 / 11$ & $0.356 / 10$ & $0.377 / 11$ & $0.377 / 11$ \\
\hline & ess_module_num & 180 & 181.5 & 186.5 & 172.5 & 172.5 \\
\hline & cs_min_pwr (W) & 20503.51 & 17276 & 15377 & 14998 & 13859 \\
\hline & cs_max_pwr (W) & 20503.51 & 37590 & 39868 & 36830 & 36071 \\
\hline & cs_lo_soc & 0.4 & 0.444 & 0.459 & 0.363 & 0.355 \\
\hline & cs_hi_soc & 0.8 & 0.827 & 0.75 & 0.75 & 0.75 \\
\hline \multirow{4}{*}{ 蒫 } & $\mathbf{t}_{1}$ & 4 & 3.5 & 3.4 & 3.6 & 3.8 \\
\hline & $\mathbf{t}_{2}$ & 38.2 & 30.5 & 28.4 & 31.7 & 34.2 \\
\hline & Grade & 12.2 & 14.1 & 14.8 & 13.9 & 13.1 \\
\hline & $\triangle \mathrm{SOC}$ & 0.5 & 0.5 & 0.5 & 0.505 & 0.645 \\
\hline
\end{tabular}

For the first and the second optimisation cases, if we favour the minimisation of the FC of our SHEV compared to the limitation of emissions, then the choice will be focused on the first case of multiobjective optimisation. And if we favour the minimisation of emissions in relation to FC, then the choice will be focused on the second case of multiobjective optimisation.

Optimisations are applied on UDDS cycle, in which its distance is $11.99 \mathrm{~km}$. To visualize the battery charge and discharge history, the optimised SHEV for the first and second optimisation cases were tested over twenty UDDS cycles, as presented in Figure 12.

The first optimisation case allows for a slower battery charge and discharge compared to the vehicle before optimisation, which increases the battery life, while, in the second case of optimisation, the minimum battery SOC exceeds $40 \%$, which allows a fast destruction of the battery. So, the first case of optimisation seems more effective for long distances as optimal SHEV. The results are very encouraging, which allows the vehicle designer to choose the optimal sizing of the SHEV drivetrain and to identify the optimal parameters of the control strategy. 

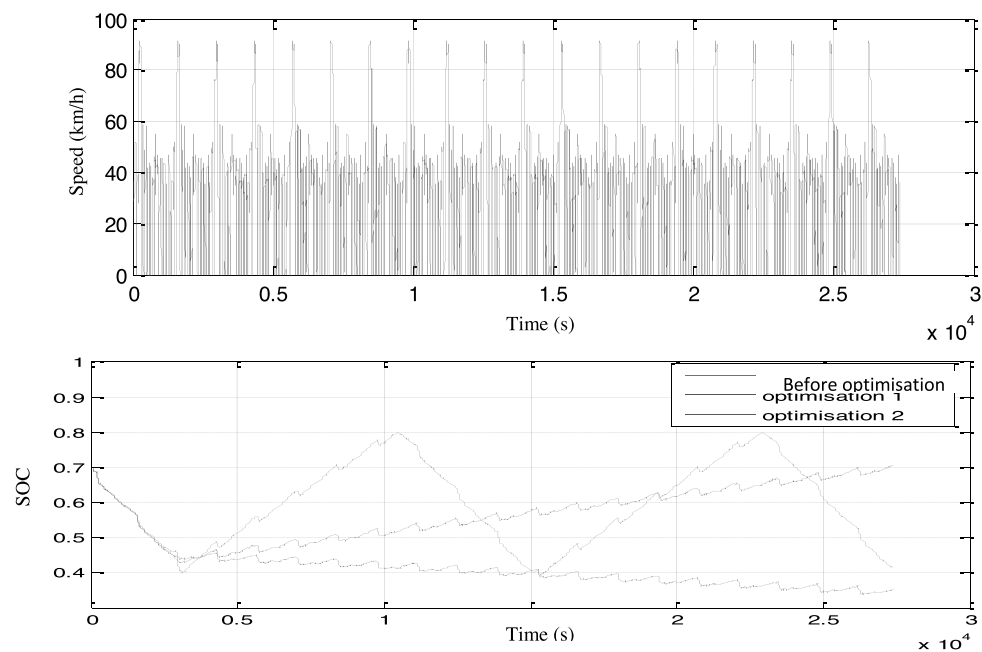

Figure 12. Battery state of charge history (during 20 UDDS cycles).

\section{OPTIMAL SHEV}

Figure 13 shows the history of the first case of multiobjective optimisation that is chosen as the optimal vehicle. The evolution of the optimisation variables, the constraints, and the standardized value of the objective function are represented.

Table 8 defines the main characteristics of the power components, as well as the TCS parameters of the optimal SHEV. The latter is characterized by a permanent magnet synchronous motor with $24 \mathrm{~kW}$ maximum powers, an ICE of $14 \mathrm{~kW}$ power, and a generator of $11 \mathrm{~kW}$. And even the mass of the vehicle slightly decreased from $1000 \mathrm{~kg}$ before optimisation to $994 \mathrm{~kg}$ after the optimisation. The performance of the new SHEV is better than the vehicle before optimisation since the power of the EM has increased.
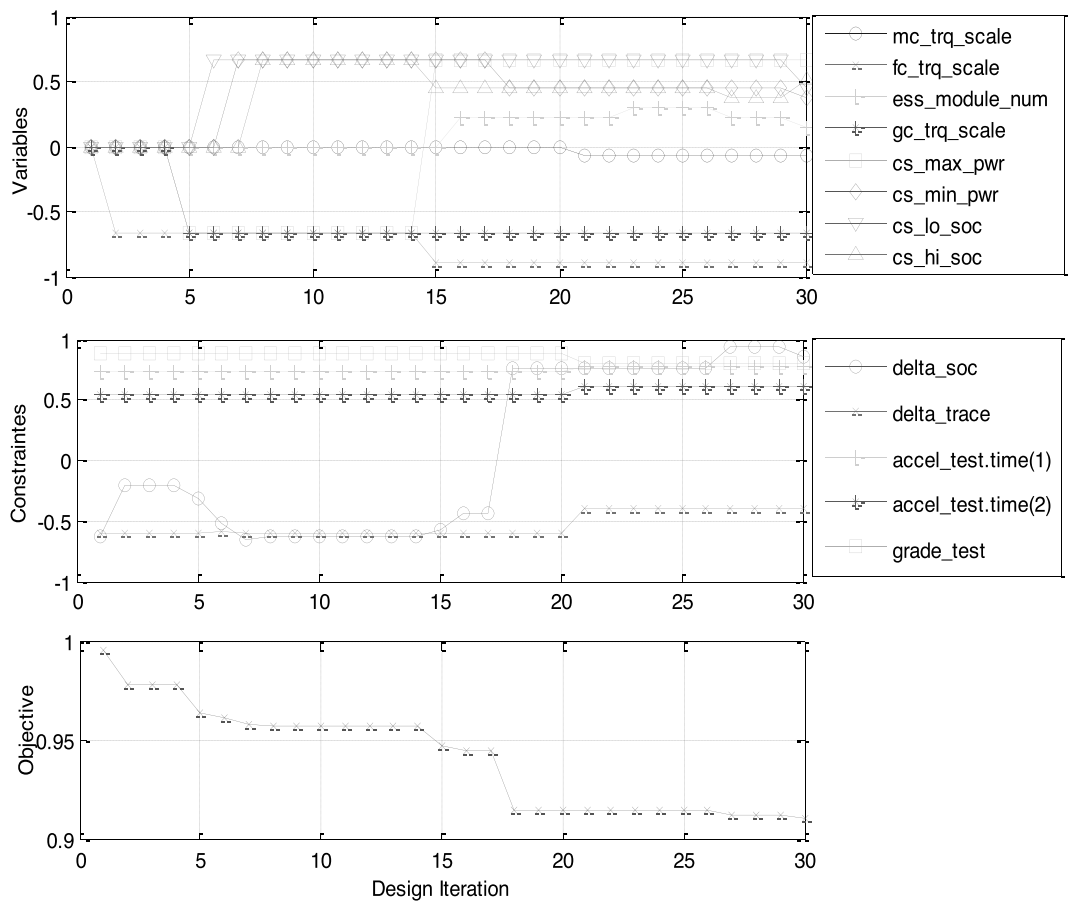

Figure 13. Simulation history of the first case of multiobjective optimisation. 
Table 8. SHEV configuration.

\begin{tabular}{|c|c|c|c|}
\hline \multicolumn{2}{|c|}{ Design parameters } & \multirow{2}{*}{$\frac{\text { Initial }}{21.5}$} & \multirow{2}{*}{$\begin{array}{c}\text { Optimal } \\
24\end{array}$} \\
\hline \multirow{4}{*}{ EM } & Max power $(\mathrm{kW})$ & & \\
\hline & Max torque $(\mathrm{Nm})$ & 111.45 & 124.8 \\
\hline & Max speed (tr/min) & 6121.34 & 6121.34 \\
\hline & Max efficiency & 0.97 & 0.97 \\
\hline \multirow{4}{*}{ ICE } & Max power $(\mathrm{kW})$ & 16 & 14 \\
\hline & Max torque $(\mathrm{Nm})$ & 32.5 & 27.26 \\
\hline & Max speed (tr/min) & 5700 & 5700 \\
\hline & Max efficiency & 0.34 & 0.34 \\
\hline \multirow{4}{*}{ Generator } & Max power $(\mathrm{kW})$ & 16 & 11 \\
\hline & Max torque $(\mathrm{Nm})$ & 58.75 & 21.8 \\
\hline & Max speed (tr/min) & 5000 & 5000 \\
\hline & Max efficiency & 0.9 & 0.9 \\
\hline \multirow{3}{*}{ Battery } & Module number & 180 & 181.5 \\
\hline & Cellule capacity (Ah) & 6 & 6 \\
\hline & Cellule number by module & 3 & 3 \\
\hline \multicolumn{2}{|c|}{ Control strategy parameters } & Initial & Optimal \\
\hline \multicolumn{2}{|c|}{ cs_hi_soc } & 0.8 & 0.827 \\
\hline \multicolumn{2}{|c|}{ cs_lo_soc } & 0.4 & 0.444 \\
\hline \multicolumn{2}{|c|}{ cs_min_pwr(W) } & 20503.515 & 17276 \\
\hline \multicolumn{2}{|c|}{ cs_max_pwr (W) } & 20503.515 & 37590 \\
\hline
\end{tabular}

Table 9 represents the gain in FC and pollutant emissions of the optimal SHEV compared to the SHEV before optimisation.

Table 9. Gain in fuel consumption and pollutant emissions of the optimal SHEV compared to the SHEV before optimisation.

\begin{tabular}{|c|c|c|c|c|}
\hline \multicolumn{2}{|c|}{} & Before optimisation & Optimal & Gain \\
\hline \multirow{2}{*}{ FC (1/100 km) } & 5.7 & 5.3 & $5.7 \%$ \\
\hline \multirow{3}{*}{$\begin{array}{c}\text { Emissions } \\
(\mathbf{g} / \mathbf{k m})\end{array}$} & $\mathbf{H C}$ & 0.209 & 0.182 & $12.91 \%$ \\
\cline { 2 - 5 } & $\mathbf{C O}$ & 1.026 & 0.808 & $21.24 \%$ \\
\cline { 2 - 5 } & $\mathbf{N O x}$ & 0.354 & 0.249 & $29.66 \%$ \\
\hline
\end{tabular}

Figure 14 shows the ICE efficiency map and the maximum generator torque for SHEV before optimisation and for optimal SHEV. The maximum torque of the generator is decreased so that it is close to the maximum yield line of the ICE. 


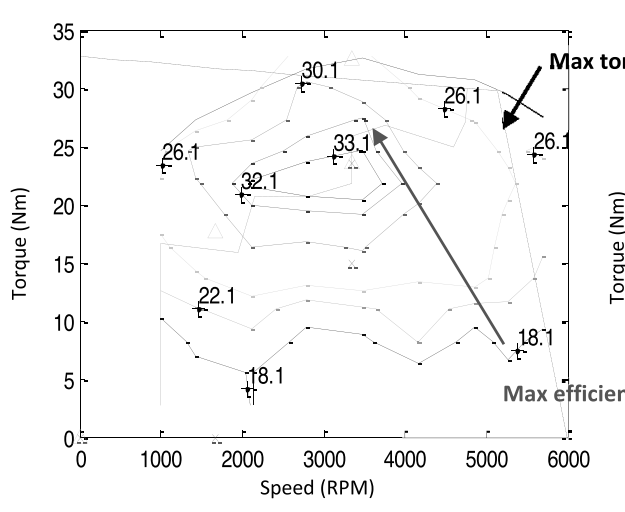

(a)

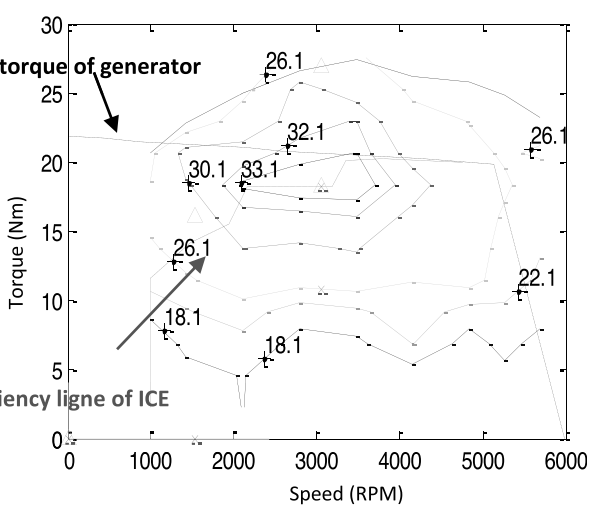

(b)

Figure 14. ICE efficiency map and generator maximum torque (a) for SHEV before optimisation and (b) for optimal SHEV along UDDS cycle.

\section{CONCLUSION}

In this study, DIRECT is used to optimise the FC and emissions while keeping a good command of the control strategy parameters and adjusting the power train components of SHEV. DIRECT was chosen because it is a deterministic, global, and without gradient algorithm, which is suitable for the vehicle optimisation problem. ADVISOR is used and combined with the fitness function to effectively evaluate the FC and emissions (HC, CO, and NOx) of the ICE. Furthermore, the driving performance requirements were satisfied. By applying the weighting aggregation method, four multiobjective optimisation cases were initiated using ADVISOR to simultaneously minimise FC and emissions while satisfying driving performance requirements. The results indicate that DIRECT algorithm helps improve the FC and reduce the emissions, as well as guarantee vehicle performance. Finally, the optimisation phase makes the SHEV more efficient, less polluting, and uses less fuel.

Obviously, the ponderation factors could be optimised, in future works, since they have an influence on the results. Also, it could be interesting to optimise the SHEV using other algorithms such as GA in order to confirm results.

\section{REFERENCES}

Abdelmoula, R. 2018. Optimisation d'une chaîne de traction Application véhicule électrique, PhD thesis, University of Sfax.

Abdelmoula, R., Ben Hadj, N., Chaieb, M. \& Neji, R. 2016. Finite element comparative analysis software of a radial flux permanent magnet synchronous motor for electric vehicle drive. Proceedings of the International Conference on Recent Advances in Electrical Systems. Tunisia.

Baumann, B.M., Washington, G., Glenn, B.C. \& al. 2000. Mechatronic design and control of hybrid electric vehicles. IEEE/ ASME Trans Mechatron. 5: 58-72.

Ben Halima, N., Ben Hadj, N., Abdelmoula, R., Chaieb, M. \& Neji, R. 2018. Sizing and Determination of Fuel Consumption and Gas Emissions in a Series Hybrid Electric Vehicle. Proceedings of the International Conference on Recent Advances in Electrical Systems ICRAES18, hamammet, Tunisia.

Borthakur, S. \& Subramanian, S.C. 2018. Design and optimisation of modified series hybrid electric vehicle powertrain. Journal of Automobile Engineering. 1-17.

Brooker, A., Haraldsson, K., Hendricks, T., Johnson, V., Kelly, K., Kramer, B., Markel, T., O’Keefe, M., Sprik, S., Wipke, K. \& Zolot, M. 2019. Advanced Vehicle Simulator (ADVISOR) Documentation. Available online: http://adv-vehicle-sim. sourceforge.net/ (accessed on 19/04/2019).

Chaeib, M. 2011. Conception, modélisation et optimisation de la motorisation d'un véhicule électrique, PhD thesis, University of Sfax.

Cheng, Y.H. \& Ching-Ming, L. 2017. Control Strategy Optimisation for Parallel Hybrid Electric Vehicles Using a Memetic Algorithm. Energies. 10: 305. 
Chen, Z., Xiong, R., Wang, K. \& Jiao, B. 2015. Optimal Energy Management Strategy of a Plug-in Hybrid Electric Vehicle Based on a Particle Swarm Optimisation Algorithm. Energies. 8: 3661-3678.

Chris, M. \& Abul Masrur, M. 2011. Hybrid Electric Vehicles: Principles and Applications with Practical Perspectives, Paris, 2011.

Deb, K. 2001. Multi objective optimisation using evolutionary algorithms, Wiley, Chichester.

Desai, C. 2010. Design and Optimisation of Hybrid Electric Vehicle Drivetrain and Control Strategy Parameters using Evolutionary Algorithms. PhD thesis. University of CONCORDIA.

Finkel, D.E. \& Kelley, C.T. 2010. Convergence Analysis of the DIRECT Algorithm. North Carolina State University Center for Research in Scientific Computation Technology.

Gao, W. \& Porandla, S.K. 2005. Design Optimisation of a Parallel Hybrid Electric Powertrain. Proceedings of the International Conference on vehicle power and propulsion.

Gao, J.P., Zhu, G.M.G., Strangas, E.G. \& Sun, F.C. 2009. Equivalent fuel consumption optimal control of a series hybrid electric vehicle. J. Automobile Engineering. 223: 1003-1018.

Hao, J., Yu, Z., Zhao, Z., Shen, P. \& Zhan, X. 2016. Optimisation of Key Parameters of Energy Management Strategy for Hybrid Electric Vehicle Using DIRECT Algorithm. Energies, 9: 997.

Janiaud, N. 2011. Modélisation du système de puissance du véhicule électrique en vue de l'optimisation de l'autonomie, des performances et des couts associés. PhD thesis. University of Paris-Sud 11.

Jones, D.R. 2001. DIRECT Global Optimisation Algorithm. Encyclopedia of Optimisation, kluwer Academic Publishers.

Jun, W., Wang, Q., Wang, P. \& Han, B. 2014. The Optimisation of Control Parameters for Hybrid Electric Vehicles Based on Genetic Algorithm. SAE Technical Paper 2014-01-1894.

Kermani, S. 2009. Gestion énergétique des véhicules hybrides : de la simulation à la commande temps réel, PhD thesis, University of Valenciennes et du Hainaut-Cambresis.

Krithika, V. \& Subramani, C. 2017. A comprehensive review on choice of hybrid vehicles and power converters, control strategies for hybrid electric vehicles. Int J Energy Res.1-24.

Montazeri-Gh, M., \& Poursamad, A. \& Ghalichi, B. 2006. Application of Genetic Algorithm for Optimisation of Control Strategy in Parallel Hybrid Electric Vehicles. J. Frankl. Inst. 343: 420-435.

Panday, A. \& Bansal, H.O. 2014. Fuel Efficiency Optimisation of Input-split Hybrid Electric Vehicle Using DIRECT Algorithm. Proceedings of the International Conference on Industrial and Information System, Gwalior, India.

Panday, A. \& Bansal, H.O. 2016. Energy Management Strategy for Hybrid Electric Vehicles Using Genetic Algorithm. J. Renew. Sustain. Energy. 8:741-746.

Rousseau, A., Pagerit, S. \& Gao, D. 2007. Plug-in Hybrid Electric Vehicle Control Strategy Parameter Optimisation. JAEV. 6:1125-1133.

Rousseau, G. 2008. Méthodologie de dimensionnement d'un moteur électrique pour véhicules hybrides. $\mathrm{PhD}$ thesis. University of PSL (Paris Sciences \& Lettres).

Shabbir, W. 2015. Control Strategies for Series Hybrid Electric Vehicles, PhD thesis, University of Nantes.

Souffran, G. 2012. Dimensionnement de la chaîne de traction d'un véhicule électrique hybride basé sur une modélisation stochastique de ses profils de mission, $\mathrm{PhD}$ thesis, University of Nantes.

Varesi, K. \& Radan A. 2011. A Novel GA Based Technique for Optimizing Both the Design and Control Parameters in Parallel Passenger Hybrid Cars. Int. Rev. Electr. Eng, 63: 1279-1286.

Wipke, K., Markel, T. \& Nelson, D. 2001. Optimizing Energy Management Strategy and Degree of Hybridization for a Hydrogen Fuel Cell SUV. Proceedings of EVS 18. Berlin.

Wu, J., Zhang, C.H. \& Cui, N.X. 2008. PSO Algorithm-based Parameter Optimisation for HEV Powertrain and Its Control Strategy. Int. J. Automot. Technol. 91: 53-59 .

Xiong, R., He, H.W. \& Sun, F.C. 2015. Methodology for Optimal Sizing of Hybrid Power System Using Particle Swarm Optimisation and Dynamic Programming. Energy Procedia. 75: 1895-1900.

Yadav, N.K. 2019. Hybridization of Particle Swarm Optimization with Differential Evolution for Solving Combined Economic Emission Dispatch Model for Smart Grid. Journal of Engg. Research, 7: 244-257.

Zhang, X. \& Chris, M. 2011. Vehicle Power Management: Modeling, Control and Optimisation, London. 